72 | Nindya Rizqi A.: Osteoinduction Ability Of Human Adiposed Derived Mesenchymal Stem Cell (HADMSC)

\title{
Osteoinduction Ability Of Human Adiposed Derived Mesenchymal Stem Cell (HADMSC) with Chitosan Scaffold Combination Towards Blood Serum Phosphorus Levels
}

\author{
Nindya Rizqi Anjani ${ }^{*}$, M. Roelianto², Latief Mooduto² \\ ${ }^{1}$ Faculty of Dentistry, Airlangga University \\ ${ }^{2}$ Department of Conservative Dentistry, Airlangga University \\ *Corresponding author: nindyaanjani@gmail.com
}

\begin{abstract}
Reconstruction of extensive bone tissue damage is a treatment with complication. Because moving the autologous tissue such as bone graft can cause complications that causes problems in the repair of extensive tissue damage so, the principle of tissue engineering (stem cells, bioreactor / growth factor, and scaffold) is used as an alternative to reconstruct damage to the tissue because it has many advantages. The combination of hADMSC and chitosan scaffold, is expected to trigger osteoinduction that can be expressed by osteogenic markers such as phosphorus levels in blood serum. To prove osteoinduction in a combination of Human Adiposed Derived Mesenchymal Stem Cell (hADMSC) and chitosan scaffold using blood serum phosphorus levels. This study used 12 groups with 5 sample each. Groups 1 to 4 were the negative control group at day 1,3,7, and 14 . While groups 5 to 8 were the positive control group at day 1,3,7, and 14 . Groups 9 to 12 were treatment groups at day 1,3,7, and 14. In the negative control group bone was only removed, in positive control group, bone was removed and chitosan scaffold was added, and in treatment group, bone was removed then, hADMSC and chitosan scaffold combination was added. Blood collection will be carried out in each group for examination of phosphorus levels in the blood serum. There were differences in phosphorus levels in blood serum in each group even though statistically there were only significant differences on day 14. The combination of hADMSC and chitosan scaffold caused a significant change in blood serum phosphorus levels on day 14 which means it triggers osteoinduction.
\end{abstract}

Keywords: Human Adiposed Derived Mesenchymal Stem Cell, chitosan scaffold, tissue engineering, phosphorus

\section{INTRODUCTION}

Tissue engineering is the application of the principles and methods of homeostatic engineering and science to the basic understanding of structural and functional relationships in normal and pathological mammalian tissues as well as the development of biological replacement to restore, maintain, or enhance tissue function (O'Brien, 2011). Tissue engineering is used in regenerative medicine which aims to repair and replace damaged or lost tissue by initiating natural regeneration 
processes, for example, osteoinduction which plays an important role in bone tissue regeneration (Nandi, 2010; Polini, 2011).

The principle of tissue engineering consists of three key elements, namely stem cells, bioreactors/growth factors, and scaffolds (O’Brien, 2011). Stem cells are unspecialized cells that can regenerate themselves over a long period of time with the potential to transform into various tissues with specific functions (Rai, 2015). The advantages of human adipose derived mesenchymal stem cells (hADMSC) are that they are widely available and easily accessible in the body with minimally invasive procedures as well as cheaper and adipose tissue is a waste of surgery (Baer \& Geiger, 2012; Hwangbo, 2010). In addition, hADMSCs exhibit stable growth, extensive self-regenerative capacity and the ability to differentiate into various cell lineages such as osteogenic, adipogenic, chondrogenic, hepatogenic, and neurogenic cells, similar to human bone-marrow derived MSCs (hBMSCs) (Laschke, 2013; Najlaa et al., 2017).

\section{METHOD}

This research is an experimental post test only control group design by looking at the level of phosphorus in blood serum from human Adipose-derived Mesenchymal Stem Cell (hADMSC) on chitosan scaffold implanted in the maxillary bone of rats. The experimental animals used in this study were male wistar rats (Rattus norvegicus) of the wistar strain, aged 3 months with an initial body weight of 300-330 g, as many as 48 tails.
Furthermore, the scaffold is used to become a template or framework for tissue formation and is seeded with stem cells (O'Brien, 2011). The choice of chitosan as a scaffold, because chitosan has been widely used in bone tissue engineering, is biocompatible, biomimetic and has shown that chitosan enhances cell growth and deposition of mineral-rich matrix by osteoblast cells (Dash et al., 2011). To determine the presence of osteoinduction in the combination of the two materials, several osteogenic markers such as RUNX2 (run-related transcription factor 2) and phosphorus (Komori, 2011) are shown (Raina et al., 2012).

This research was conducted in vivo by administering a combination of adipose derived mesenchymal stem cells taken from human adipose tissue that had been seeded in chitosan scaffold in the maxillary bone of wistar rats and examined using RUNX2 markers and phosphorus in blood serum as markers of osteoinduction.

The sample size in this study (each group) was calculated using the Federer formula, which is as follows:

Description : $n=$ number of samples for each treatment group

$\mathrm{t}=$ number of treatment groups

$$
\begin{aligned}
& (\mathrm{t}-1)(\mathrm{n}-1) \quad \geq 15 \\
& (12-1)(\mathrm{n}-1) \geq 15 \\
& \mathrm{n}-1 \quad \geq 15 / 11 \\
& \mathrm{n} \quad \geq 2,3 \\
& \mathrm{n} \quad \geq 3
\end{aligned}
$$


Based on the Federer formula listed above, 3 samples were used in each experimental group. Therefore, this study used 48 rats with 12 as reserves, which were divided into 12 groups.

This study was conducted to analyze serum phosphorus levels in human Adipose Derived

\section{RESULTS}

This research was conducted in vivo by administering a combination of human adipose derived mesenchymal stem cells taken from human adipose tissue that had been seeded in chitosan scaffold on the maxillary bone of burried wistar rats. The toxicity test of chitosan scaffold on human adipose derived mesenchymal stem cells using the MTT assay method was carried out
Mesenchymal Stem Cells (hADMSC) after chitosan scaffold was administered to the maxillary bone of rats. Data on serum phosphorus levels were tabulated and statistical analysis was performed using the one way Annova test.

at the Stem Cell Research Center, Universitas Airlangga.

Observation of the osteoinduction ability of the combination of human adipose derived mesenchymal stem cell and chitosan scaffold was carried out in 12 groups by measuring the level of phosphorus in the blood serum of rats from each sample and expressed in units $(\mathrm{mg} / \mathrm{dl})$ in the table.

Table 1 Measurement results of serum phosphorus levels $(\mathrm{mg} / \mathrm{dl})$ on the first day.

\begin{tabular}{|c|c|c|c|}
\hline \multirow{2}{*}{ Sample } & \multicolumn{3}{|c|}{ First day (N1) } \\
\cline { 2 - 4 } & Negative Control & $\begin{array}{c}\text { Positive } \\
\text { Control }\end{array}$ & $\begin{array}{c}\text { Treatmen } \\
\text { t }\end{array}$ \\
\hline 1 & 7 & 9 & 9.1 \\
\hline 2 & 7.5 & 9.1 & 10.9 \\
\hline 3 & 7.9 & 7.2 & 6.7 \\
\hline 4 & 8 & 5.3 & 8.7 \\
\hline $\begin{array}{c}\text { Aver } \\
\text { age }\end{array}$ & 7.6 & 7.65 & 8.85 \\
\hline
\end{tabular}

Table 2 Measurement results of serum phosphorus levels $(\mathrm{mg} / \mathrm{dl})$ on the third day

\begin{tabular}{|c|c|c|c|}
\hline \multirow{2}{*}{ Sample } & \multicolumn{3}{|c|}{ Third day (N3) } \\
\cline { 2 - 4 } & $\begin{array}{c}\text { Negative } \\
\text { Control }\end{array}$ & $\begin{array}{c}\text { Positive } \\
\text { Control }\end{array}$ & Treatment \\
\hline 1 & 6 & 8.3 & 4.8 \\
\hline 2 & 6.8 & 8.6 & 7 \\
\hline 3 & 6.2 & 6.2 & 6.7 \\
\hline 4 & 7.9 & 9.2 & 7.9 \\
\hline Average & 6.725 & 8.6 & 6.6 \\
\hline
\end{tabular}

Table 3 Measurement results of serum phosphorus levels $(\mathrm{mg} / \mathrm{dl})$ on the seventh day 


\begin{tabular}{|c|c|c|c|}
\hline \multirow{2}{*}{ Sample } & \multicolumn{3}{|c|}{ Seventh day (N7) } \\
\cline { 2 - 4 } & $\begin{array}{c}\text { Negative } \\
\text { Control }\end{array}$ & Positive Control & Treatment \\
\hline 1 & 9.7 & 9 & 8.2 \\
\hline 2 & 8.8 & 8.8 & 8.8 \\
\hline 3 & 9.7 & 6.6 & 8.4 \\
\hline 4 & 9.4 & 7 & 6.6 \\
\hline Average & 9.4 & 7.85 & 8 \\
\hline
\end{tabular}

Table 4 Measurement results of serum phosphorus levels (mg/dl) on the fourteenth day.

\begin{tabular}{|c|c|c|c|}
\hline \multirow{2}{*}{ Sample } & \multicolumn{3}{|c|}{ Fourteenth day (N14) } \\
\cline { 2 - 4 } & $\begin{array}{c}\text { Negative } \\
\text { Control }\end{array}$ & Positive Control & Treatment \\
\hline 1 & 8 & 8.4 & 6.4 \\
\hline 2 & 8.6 & 6.8 & 9 \\
\hline 3 & 9.8 & 5.6 & 7 \\
\hline 4 & 9.6 & 6.4 & 7.1 \\
\hline Average & 9 & 6.8 & 6 \\
\hline
\end{tabular}

The data from this study in the form of phosphorus levels need to be analyzed first using the One-Sample Kolmogorov-Smirnov test to determine the normal distribution of the research results and the test of homogeneity of variances to determine the homogeneity of the research results. After performing the two statistical tests, a one-way Anova statistical test can be performed to determine the differences between sample groups. The results of the normality test can be seen in the table.

Table 5 Normality test results

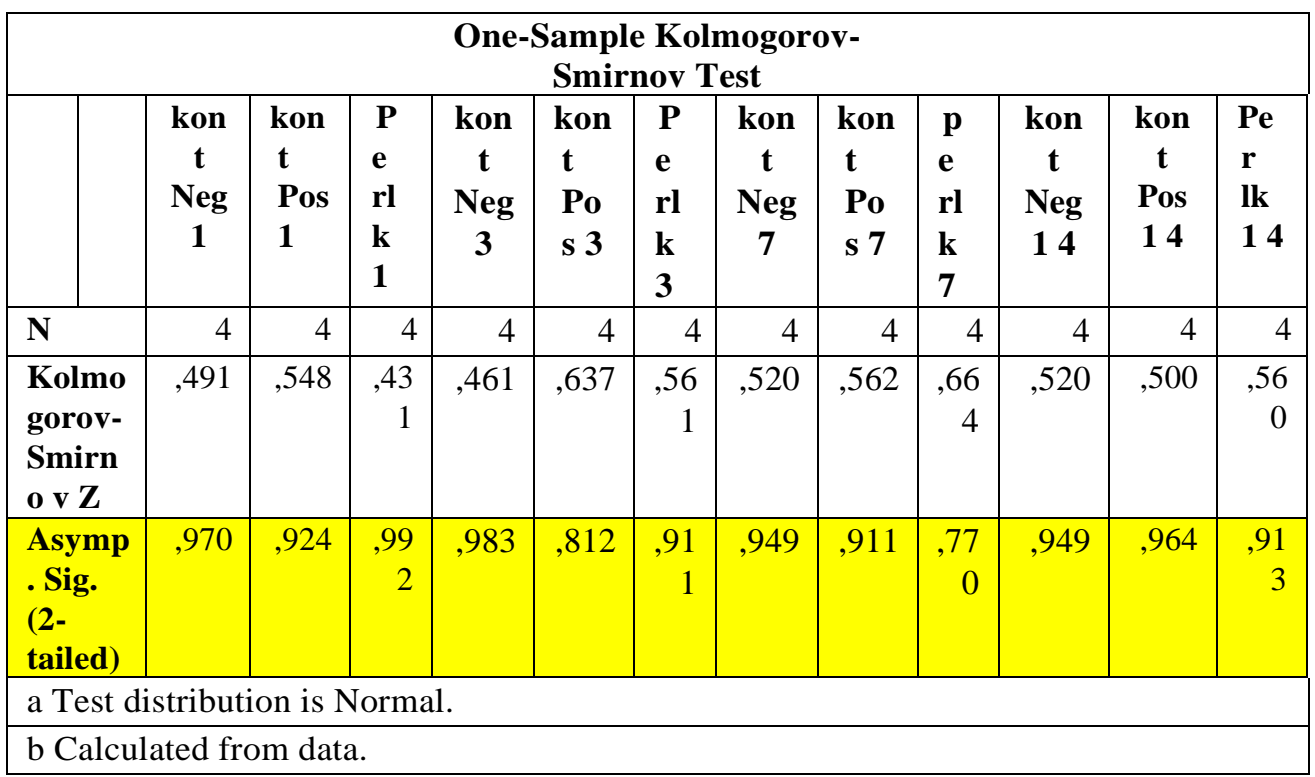

Based on the results of the normality test for serum phosphate levels using the one sample
Kolmogorov-Smirnov Test, it is known that the data is normally distributed because it has a p- 
value $>0.05$. Based on the results of the homogeneity test of serum phosphate levels, it is known that the overall data is homogeneous because it has a p-value $>0.05$.

Table 6 Homogeneity test results

\begin{tabular}{|l|r|r|r|r|}
\hline \multicolumn{5}{|c|}{ Test of Homogenity of Variances } \\
\hline & Levene Statistic & df1 & df2 & Sig. \\
\hline fosfat1 & 1,948 & 2 & 9 &, 198 \\
\hline fosfat3 &, 257 & 2 & 9 &, 779 \\
\hline fosfat7 & 4,527 & 2 & 9 &, 044 \\
\hline fosfat14 &, 162 & 2 & 9 &, 853 \\
\hline
\end{tabular}

To find out the significant differences in all treatment groups, a one-way Anova test was carried out. On the first day, third day, and seventh day, the p-value is greater than the avalue $(p>0.05)$ so it can be concluded that the phosphate level on the third to seventh day is not significant. However, on the fourteenth day, the test results showed a $\mathrm{p}$ value smaller than a $(\mathrm{p}<$ 0.05) which could be concluded that the phosphate level on day 14 had a significant value. between treatment groups.

Table 7 ANOVA test results

\begin{tabular}{|c|c|c|c|c|c|c|}
\hline & & $\begin{array}{c}\text { Sum of } \\
\text { Squares }\end{array}$ & df & $\begin{array}{c}\text { Mean } \\
\text { Square }\end{array}$ & $\mathbf{F}$ & Sig. \\
\hline \multirow[t]{3}{*}{ fosfat1 } & $\begin{array}{l}\text { Between } \\
\text { Groups }\end{array}$ & 4,007 & 2 & 2,003 & ,940 & , 426 \\
\hline & Within Groups & 19,180 & 9 & 2,131 & & \\
\hline & Total & 23,187 & 11 & & & \\
\hline \multirow[t]{3}{*}{ fosfat3 } & $\begin{array}{l}\text { Between } \\
\text { Groups }\end{array}$ & 5,352 & 2 & 2,676 & 1,943 & , 199 \\
\hline & Within Groups & 12,395 & 9 & 1,377 & & \\
\hline & Total & 17,747 & 11 & & & \\
\hline \multirow[t]{3}{*}{ fosfat7 } & $\begin{array}{l}\text { Between } \\
\text { Groups }\end{array}$ & 5,847 & 2 & 2,923 & 3,352 & ,082 \\
\hline & Within Groups & 7,850 & 9 & 872 & & \\
\hline & Total & 13,697 & 11 & & & \\
\hline \multirow[t]{3}{*}{ fosfat14 } & $\begin{array}{l}\text { Between } \\
\text { Groups }\end{array}$ & 11,387 & 2 & 5,693 & 4,402 & ,046 \\
\hline & Within Groups & 11,640 & 9 & 1,293 & & \\
\hline & Total & 23,027 & 11 & & & \\
\hline
\end{tabular}




\section{DISCUSSION}

This study was conducted in vivo to prove whether there was a change in the level of phosphorus in the blood serum as an indication of osteoinduction after administration of a combination of Human Adiposed Derived Mesenchymal Stem Cell (hADMSC) and chitosan scaffold in the maxillary bone defects of wistar rats. The use of Human Adiposed Derived Mesenchymal Stem Cells is in accordance with (Aksu et al., 2008) which states that Human Adiposed Derived Mesenchymal Stem Cells can differentiate into osteoblast like cells. The use of Chitosan as a scaffold in this study was based on research (Dash et al., 2011) which stated that chitosan increased cell growth and deposition of mineral-rich matrix by osteoblasts.

From the results of the study, a one-way Anova test was carried out to see statistically whether there was a significant difference in results. Statistical analysis showed that the comparison of blood levels of phosphorus in the negative control, positive control and treatment on the first, third and seventh days there was no significant difference or not. significant, because the value of $\mathrm{p}(\mathrm{Sig})$ shows a number above 0.05 . A significant difference or significance between the treatment groups was only seen on the fourteenth day, because the $\mathrm{p}(\mathrm{Sig})$ value showed a number below 0.05 .

On the first day, there was no significant difference in the level of phosphorus in the blood because the bone healing process that definitely occurred on the first day was an inflammatory process where there was no significant process of bone resorption and mineralization that could affect the level of phosphorus in the blood according to (Mountziaris \& Mikos, 2008). However, in the results of the study, there were still differences in phosphorus levels from each group, with the average phosphorus levels of the treatment being higher than the positive control and negative control. The high levels of phosphorus in the treatment could occur due to several possibilities, including a higher dietary intake of phosphate than other groups and an increase in PTH more than the other groups because the number of Mesenchymal Stem Cells in the treatment group was higher than the other groups so that it would increase absorption. phosphate in the intestine (Raina et al., 2012).

Then, on the third day there was also no significant difference in phosphorus levels in the blood because in the bone healing process what happened was the proliferation of hADMSCs and the differentiation of preosteoblasts into osteoblasts which had no significant effect on serum phosphate in the blood according to (Dimitriou et al., 2005; Mountziaris \& Mikos, 2008). However, in the results of the study, the lowest phosphorus levels were found in the treatment when compared to the negative control which was probably due to the lower dietary intake of phosphate compared to other groups and the ongoing osteogenic differentiation of hADMSCs that required PTH so that there would be a decrease in PTH which would reduce absorption. calcium and phosphate in the intestine (Penido \& Alon, 2012). 
On the seventh day, there was no significant difference in the level of phosphorus in the blood serum because in the normal bone healing process, what occurred on the seventh day was a continuation of the same process from the third day, namely the peak of MSCs cell proliferation in intramembranous ossification. From the results of the seventh day study, phosphorus levels in the positive control and treatment were lower than phosphorus levels in the negative control, which could occur due to lower dietary phosphate intake and the process of changing the osteogenic differentiation of hADMSCs requiring PTH has been completed.

On the fourteenth day, there was a significant or significant difference in phosphorus levels in blood serum. This is because the fourteenth day is the most active phase of osteogenesis until day 21 is characterized by the cessation of cell proliferation in

\section{REFERENCES}

Aksu, A. E., Rubin, J. P., Dudas, J. R., \& Marra, K. G. (2008). Role of gender and anatomical region on induction of osteogenic differentiation of human adipose-derived stem cells. Annals of Plastic Surgery, 60(3), 306-322.

Baer, P. C., \& Geiger, H. (2012). Review Article Adipose-Derived Mesenchymal Stromal/Stem Cells: Tissue Localization, Characterization, and Heterogeneity. Stem Cells International, 2012.

Dash, M., Chiellini, F., Ottenbrite, R., \& Chiellini, E. (2011). "Chitosan-A versatile intramembranous ossification, mineralization of soft callus, cartilage resorption, woven bone formation, and the beginning of the bone remodeling phase which most affects phosphorus levels. in the blood due to the process of mineralization and resorption in accordance with (Dimitriou et al., 2005; Mountziaris \& Mikos, 2008). Based on the results of the study, the levels of phosphorus in blood serum in the positive control and treatment were significantly lower than the negative control due to the higher mineralization ratio in the positive control and treatment in accordance with (Penido \& Alon, 2012) which stated that the presence of increased mineralization will decrease the concentration of phosphorus and calcium in the serum, and increased bone resorption will increase the concentration of phosphorus and calcium in the serum.

semi-synthetic polymer in biomedical applications." Progress in Polymer Science, 36(8), 981-1014.

Dimitriou, R., Tsiridis, E., \& Giannoudis, P. V. (2005). Current concepts of molecular aspects of bone healing. Injury International. Journal Care, 36, 13921404.

Hwangbo, S. (2010). Therapeutic Potential of Human Adipose Stem Cells in a Rat Myocardial Infarction Model. Yonsei Medical Journal, 51(1), 69-76.

Komori, T. (2011). Signaling Networks in RUNX2-Dependent Bone Development. 
Journal of Cellular Biochemistry, 112, 750755.

Laschke, M. (2013). "Three-dimensional spheroids of adipose-derived mesenchymal stem cells are potent initiators of blood vessel formation in porous polyurethane scaffolds.” Acta Biomaterialia, 9(6), 68766884.

Mountziaris, P. M., \& Mikos, A. G. (2008). Modulation of the Inflammatory Response for Enhanced Bone Tissue Regeneration. Tissue Engineering: Part B, 14(2), 179186.

Najlaa, M., Eman, A., Ibrahim, M., Hazem, M., \& Khaled, H. (2017). Regeneration of Pulp/Dentin-Like Tissue in Immature Necrotic Permanent Dog Teeth Using Adipose Tissue-Derived Mesenchymal Stem Cells. Journal Hyg Health, 5, 217.

Nandi, S. (2010). Orthopaedic applications of bone graft \& graft substitutes: a review.
Indian Journal of Medical Research, 132, $15-30$.

O’Brien, F. J. (2011). "Biomaterials \& scaffolds for tissue engineering." Materials Today, 14(3), 88-95.

Penido, M. G., \& Alon, U. S. (2012). Phosphate homeostasis and its role in bone health. Pediatric Nephrology, 27, 2039-2058.

Polini, A. (2011). "Osteoinduction of Human Mesenchymal Stem Cells by Bioactive Composite Scaffolds without Supplemental Osteogenic Growth Factors.” PLos ONE, $6(10)$.

Rai, R. (2015). Tissue Engineering : Step Ahead in Maxillofacial Reconstruction. 7(9), 138142.

Raina, R., Garg, G., Sethi, S. K., Schreiber, M. J., Simon, J. F., \& Thomas, G. (2012). Phosphorus Metabolism. Journal of Nephrology \& Therapeutics, 3(8). 